\title{
Densidade do pitiguari (Cyclarhis gujanensis) em dois tipos de habitat florestais no Parque Estadual Mata do Godoy, norte do estado do Paraná
}

\section{Density of the rufous-browed peppershrike (Cyclarhis gujanensis) in two forest habitat types in the Parque Estadual Mata do Godoy, northern of the state of Paraná}

\author{
Thaís Fernanda de Assis ${ }^{1}$; Luiz dos Anjos ${ }^{2}$
}

\begin{abstract}
Resumo
O pitiguari (Cyclarhis gujanensis) está associado às áreas com árvores e borda de floresta. Neste estudo a densidade desta espécie de ave foi comparada em dois tipos de habitats florestais no Parque Estadual Mata do Godoy, norte do Paraná, sul do Brasil. O primeiro habitat encontra-se perto de uma clareira e outro no interior da floresta. O método de transecção e o software Distance 6.0 foram utilizados para obter a densidade do pitiguari. A densidade foi maior no habitat próximo a clareira $(14,88$ indivíduos/ $\left.\mathrm{km}^{2}\right)$ do que no interior de floresta $\left(2,51\right.$ indivíduos $/ \mathrm{km}^{2}$; Teste $\left.\mathrm{G}=9,47, \mathrm{gl}=1, \mathrm{P}<0.01\right)$. A alta densidade em clareiras sugere que esta ave pode ser favorecida com a fragmentação da floresta e que seu aumento populacional pode ser usado como um indicador biológico de áreas perturbadas.

Palavras-Chave: Clareira. Indicador biológico. Borda de floresta.
\end{abstract}

\begin{abstract}
The rufous-browed peppershrike (Cyclarhis gujanensis) is associated to woodland and forest edges. In this study the density of this bird species was compared in two types of forest habitats in the Godoy State Park, northern Paraná, southern Brazil. The first habitat was close to clearings and the other was in the forest interior. The transect method and the Distance 6.0 software were used to obtained the density of the rufous-browed peppershrike. The density was higher in the habitat close to clerarings $(14.88$ individuals $/ \mathrm{km}^{2}$ ) than in the forest interior (2.51 individuals $/ \mathrm{km}^{2}$; Teste $\mathrm{G}=9,47, \mathrm{gl}=1, \mathrm{P}<0.01$ ). The high density in clearings suggest that this bird can be favor with forest fragmentation and that its population increase could be used as a biological indicator of disturbed areas.
\end{abstract}

Keywords: Clearings. Biological indicator. Forest edge.

${ }^{1}$ Graduação em Ciências Biológicas, Universidade Estadual de Londrina (UEL), Londrina, Paraná. E-mail: thata86_assis@hotmail. com

${ }^{2}$ Departamento de Biologia Animal e Vegetal. Centro de Ciências Biológicas. Universidade Estadual de Londrina, Londrina, Paraná, Brasil. E-mail: 1lanjos@sercomtel.com 


\section{Introdução}

O pitiguari, Cyclarhis gujanensis (GMELIN, 1789), é um pássaro silvícola. Está presente desde o México até a Argentina, ocorrendo em todas as regiões do Brasil (SICK, 1997), exceto em uma pequena área da Amazonia Ocidental (ANTAS, 2004). Seus hábitos estão associados à vegetação aberta ou bordas de floresta (BELTON, 1994; RIDGEGLY; TUDOR, 1994; SICK, 1997). Também ocorre em regiões urbanizadas como parques e quintais bem arborizados (BELTON, 1994). Evita áreas contínuas de floresta, especialmente em regiões úmidas (WILLIS; ONIKI, 2003).

No presente estudo, comparou-se a densidade do pitiguari em dois tipos de habitats no Parque Estadual Mata do Godoy (PEMG). Considerando a literatura disponível, espera-se obter uma densidade maior do pitiguari em habitats próximos às clareiras do PEMG do que naqueles compostos por floresta contínua.

\section{Material e Métodos}

Área de estudo. $\mathrm{O}$ presente estudo foi

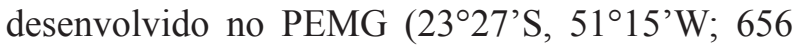
ha), $15 \mathrm{~km}$ ao sul da cidade Londrina, o qual é constituído principalmente por contínua Floresta Estacional Semidecídua em bom estado de conservação (SILVEIRA, 2006). Espécies arbóreas típicas desta formação são: Cabralea canjerana (Meliaceae), Ocotea indecora (Lauraceae), Nectandra megapotamica (BIANCHINI et al., 2003), Apidosperma polyneuron (Apocynaceae), Solanea monosperma (Elaeocarpaceae) e Galesia integrifolia (Phytolaccaceae) (TOREZAN, 2003).

Procedimentos em campo. Comparou-se a densidade populacional do pitiguari em dois trechos de uma transecção no PEMG: um trecho constituído por uma estreita estrada no interior da floresta e outro composto por uma trilha no interior da floresta. O primeiro trecho (trecho 1), com 700m de extensão, corresponde a uma estreita estrada com $2 \mathrm{~m}$ de largura. $\mathrm{O}$ segundo trecho (trecho 2), com 2300m de extensão corresponde a uma trilha no interior da floresta contínua do PEMG. Para obtenção da densidade do pitiguari nos dois habitats foi utilizado o método de transecção (BIBBY; BURGESS; HILL, 1992). A transecção determinada tinha $3000 \mathrm{~m}$ e foi percorrida semanalmente de novembro de 2009 a fevereiro de 2010, iniciandose o percurso da transecção sempre uma hora após o amanhecer. A cada semana invertia-se o sentido da transecção e o tempo gasto para percorrê-la era de aproximadamente 4 horas, mantendo uma velocidade constante. O primeiro autor fez todos os registros e cada indivíduo era registrado apenas uma vez em cada dia (BIBBY; BURGESS; HILL, 1992). Os registros eram visuais e/ou auditivos. Em cada registro foi anotada a distância (esta era ilimitada) da ave em relação à transecção e o ângulo em relação ao observador (BIBBY; BURGESS; HILL, 1992). Tal procedimento permitiu obter a densidade da espécie em cada trecho da transecção, utilizandose o software Distance 6.0. Utilizou-se o teste $\mathrm{G}$, para avaliar se há diferença significativa $(\alpha=0,05)$ entre as densidades nos dois trechos da transecção (FOWLER; COHEN, 1986). Para calcular a densidade no software Distance 6.0 são necessários ao menos 40 contatos da espécie em foco.

\section{Resultados e Discussão}

O pitiguari foi encontrado nos dois trechos, com 122 registros no total, sendo 72 no trecho 1 e 50 no trecho 2. A densidade do pitiguari foi significativamente maior no trecho $1 \quad(14,88$ indivíduos $/ \mathrm{km}^{2}$ ) do que no trecho 2 (2,51 indivíduos/ $\mathrm{km}^{2}$; Teste $\left.\mathrm{G}=9,47, \mathrm{gl}=1, \mathrm{P}<0.01\right)$.

A maior densidade no trecho 1 (estrada) sugere que o pitiguari está realmente mais associado à borda de floresta, como indicam diversos autores (BELTON, 1994; RIDGELY; TUDOR, 1994; SICK, 1997). No caso de florestas contínuas, esta espécie deve ocupar preferencialmente a borda de clareiras. 
Os desmatamentos, e a consequente fragmentação da floresta, devem favorecer esta espécie pelo aumento da área de borda disponível. Portanto, o aumento da densidade do pitiguari deve estar associado a perturbações causadas pelo homem. $\mathrm{O}$ aumento da densidade do pitiguari pode ser, portanto, utilizado como uma indicação biológica de áreas com perturbação antrópica.

\section{Agradecimentos}

Bolsas de Iniciação Científica foram concedidas ao primeiro autor e de Produtividade em Pesquisa ao segundo autor (302694/2010-2) respectivamente pela Fundação Araucária e pelo CNPq. O Instituto Ambiental do Paraná concedeu permissão de estudo no Parque Estadual Mata do Godoy. A Barbara Rocha Arakaki, Gabriela Menezes Bochio, Andrea Larissa Boesing e Gabriel Lima Medina Rosa, do Laboratório de Ornitologia e Bioacústica da Universidade Estadual de Londrina, pela ajuda na identificação dos cantos do Pitiguari e análise estatística dos dados.

\section{Referências}

ANTAS, P. T. Z. Pantanal: guia de ave de espécie da reserva particular do patrimônio natural do SESC do Pantanal. Rio de Janeiro: Sesc, 2004.

BELTON, W. Aves do Rio Grande do Sul: distribuição e biologia. São Leopoldo: Unisinos, 1994.

BIANCHINI, E.; POPOLO, R. S.; DIAS, M. C.; PIMENTA, J. A. Diversidade e estrutura de espécies arbóreas em área alagável no Município de Londrina, Sul do Brasil. Acta Botânica Brasílica, Porto Alegre, v. 17, n. 3, p. 405-419, 2003.

BIBBY, C. J.; BURGESS, N. D.; HILL, D. A. Bird census techniques. San Diego: Academic Press, 1992.

FOWLER, J.; COHEN, L. Statistics for Ornithologists. Leicester, UK: British Trust for Ornithology, 1986.

GMELIN, J. F. Caroli a Linne, systema naturae per regna tria naturae, secundum classes, ordines, genera, species, cum characteribus, differentiis, synonymis, locis. Editio decima tertia, aucta reformata, Tomus 1, Regnum Animale, Pars II. Lipsiae: Impensis Georg Emmanuel Beer, 1789.
RIDGELY, R. S.; TUDOR, G. The birds of South America. Austin: Texas Press, 1994.

SICK, H. Ornitologia brasileira: uma introdução. Rio de Janeiro: Nova Fronteira, 1997.

SILVEIRA, M. A. Vegetação do Parque estadual mata do Godoy. In: TOREZAN, J. M. D. (Org.). Ecologia do Parque Estadual Mata do Godoy. Londrina: ITEDES, 2006. p. 19-27.

TOREZAN, J. M. D. Fragmentação florestal e prioridades para a conservação da biodiversidade. 2003. Tese (Doutorado em Engenharia) - Escola de Engenharia de São Carlos, Universidade de São Paulo, São Carlos.

WILLIS, E. O.; ONIKI, Y. Aves do estado de São Paulo. Rio Claro: Divis, 2003.
Recebido em 04 de setembro de 2010 Aceito em 17 de outubro de 2012 
